East Africa to be conceived and established without direct financial support from government sources; it is autonomous and receives its entire funds from the tea industry. Close and friendly liaison has been maintained between the Institute ; the East African Advisory Council for Agriculture, Animal Industry and Forestry ; the Departments of Agriculture and the East African Agriculture and Forestry Research Organization through the members of the governing body and the director.

In his reply, Sir Philip Mitchell congratulated the tea industry on the inauguration of its own research station, and particularly for having worked on an inter-territorial basis. $\mathrm{He}$ traced the growing importance of the tea crop in the economy of East Africa from the early stages at the turn of the nineteenth century when private enterprise in Kenya, and government enterprise at the Botanic Gardens, Entebbe, and the Amani Institute in the then German East Africa, almost simultaneously introduced the first plants of Camellia sinensis to reach East Africa. The tea industry reached a commercial basis in 1921, and it is an expanding one. The present is therefore a very opportune time for a commodity research station to begin its work. The combination of science and practice is essential for every progressive industry; and money contributed to the support of the Institute would be in the nature of a well-spent insurance policy.

Dr. T. Eden, director of the Institute, thanked Sir Philip for formally opening the laboratories. The ceremony was followed by an inspection of the laboratories, where demonstrations and exhibits relating to the work of the Institute were on view.

\section{RECENT RESEARCH ON ELECTRICAL CONTACTS}

U

NDER the auspices of the East Midland Centre of the Institution of Electrical Engineers, a convention on "Electrical Contacts" was held at Loughborough College during April 7-9. The large attendance included members of the electrical, metallurgical and communication industries, of government research establishments and universities, as well as representation from the Netherlands, Belgium, France and Sweden. The convention was opened by Dr. W. G. Radley, engineer-in-chief of the Post Office, who stressed the important part played by contacts in modern communications: for example, in the thirty-year life of a Post Office relay the contact may operate up to $10^{3}$ times; a call between subscribers in the London area may involve 500 contacts; in the British telephone system there are altogether about 3,000 million contacts; and failure in any of these can interrupt or distort the signal.

After Dr. L. B. Hunt (Johnson Matthey and Co., Ltd.) had outlined the requirements that must be fulfilled by a contact material, Dr. A. Fairweather (Post Office Research Station, Dollis Hill) described observations on the behaviour of contacts tarnished by exposure to the atmosphere (sulphide film on silver contacts, and oxide and carbonate film on others); what happens when film-bearing contacts are pressed together; and the properties of sliding contacts at low voltage and low mechanical pressure. A film can be broken either by high pressure or high voltage, so that the resistance of the contact depends entirely on the conditions under which it is measured ; for example, a contact may have a resistance of megohms under a voltage of a millivolt, while it may be practically zero under a hundred volts. Dr. Fairweather gave detailed consideration to the change of conductance of a pair of static contacts with time due to progressive tarnishing, and indicated the effects of surface plating. Plating is not always a successful solution of the tarnish problem; for example, a soft plating, such as gold, cannot break a tarnish film on iron-chromium. The rate of corrosion may be increased by a porous plating. Again, if the plating is hard and the substrate soft, the base may sag and the unsupported plating crack under pressure. Contact noise may be due to a moving contact bumping on and off the tract formed through the film on the other contact, and also due to the electrical breakdown of the film, which is usually the important cause; the contact film will be repeatedly broken if, as in practice, the contact is not made at exactly the same place each time. To avoid noise, noble metals must be used. The effect of lubricating the contact with poly-tetrafluoroethylene, which forms a film that remains thin, was also considered.

Dr.A. L. Allen (Ericsson'Telephones) dealt with longlife contacts for unidirectional currents of 1-20 amp. and indicated the problems found in the use of vibrator contacts. He has measured erosion craters in contact electrodes by using a 'Perspex' replica technique. His conclusion was that the use of bi-metallic contacts is not a promising method of eliminating transfer unless the number of operations is small. Experiments designed to determine contact resistance were then described: tungsten in air is covered with a high-resistance oxide film, as is chromium, but the contact resistance falls when the contacts operate in a rare-gas atmosphere. Dr. Allen concluded that mechanical wear of contacts is insignificant compared with electrical wear ; copperpalladium has a low rate of transfer; and the search for new alloys is not a promising solution. $\mathrm{He}$ suggested the elimination of transfer by installing parallel circuits to prevent the contact voltage rising above the boiling voltage.

Miss J. Warham (Electrical Research Association) described the effect of inductance on fine transfer between platinum contacts in a $6-\mathrm{V}$. circuit with currents of the order of 1 amp. and controlled circuit inductance of $0.05-10 \mu \mathrm{H}$. Transfer is measured by optical examination of the pips formed on the cathode after a large number $\left(10^{5}\right)$ of operations. The results show that there is a residual transfer at break which is independent of the circuit inductance. This is bridge transfer, which can be explained by the Thomson effect in accordance with Davidson's formula for the shift of the hottest cross-section. Transfer is dependent on inductance when this is greater than $0.3 \mu \mathrm{H}$., and this is attributed to a short are.

Dr. P. M. Davidson (Physics Department, University College of Swansea) outlined the results of calculations which trace in detail the changes in the micro-geometry of the successive stages in the separation of two electrodes. The succession of shapes assumed by a liquid bridge under the action of surface tension includes nodoid shapes and unduloid shapes, of which the cylinder is a particular case. The particular form will depend on the properties of the particular metal (such as the variation of specific resistance with temperature) and how the current changes as the contact potential increases. Slides illustrating the computed results in typical cases were shown. The 
influence of the Thomson effect, variation of surface tension with temperature and surface purity, and also the influence of electrodynamic forces were discussed; internal circulating motion in the liquid and modification of the shape of the bridge will be produced. A possible theoretical explanation was proposed for the reported breaking of bridges below the boiling voltage under certain conditions.

The formation and properties of molten metal bridges was discussed by R. H. Jones (Physics Department, University College of Swansea), who analysed the various theories which have been advanced to account for bridge transfer, paying particular attention to temperature distribution in a contact. He described experimental work on the pip and crater formed in a single contact operation, and showed slides illustrating in detail the growth and rupture of the bridge both with single-metal and bi-metallic contacts. Mr. Jones considers that his results can be explained on the basis of the Thomson effect for single-metal contacts and by also taking into account the differing thermal and electrical properties of the metals in a bi-metallic contact.

Prof. F. Llewellyn Jones (Physics Department, University College of Swansea) spoke on the erosion produced by electrical discharges and analysed the basic processes occurring at both the 'make' and the 'break' phases of contact operation. He emphasized the hitherto unsuspected importance of low-voltage discharge phenomena which can occur between electrodes just about to meet $\left(\sim 10^{-4} \mathrm{~cm}\right.$. apart). The problem consists of finding the source and emission mechanisms of the electrons which initiate the discharge and also the means by which the electron current is amplified to produce a discharge avalanche. He reported experiments, carried out with E. T. de la Perrelle and G. G. Morgan, in which the rate of electron emission from cold metal surfaces was investigated by using a pulse technique in which the production of a single electron could be recorded. Comparatively high electron emission from contact surfaces was obtained with electric fields as low as $10^{4} \mathrm{~V} . / \mathrm{cm}$, and the variation of the emission with electric intensity showed that the mechanism was field emission. The emission depended very greatly on the nature of the electrode surface; for example, a thin oxide tarnish layer enhanced the emission at least a thousand times, while the presence of dust (due to the condensation of metal evaporated by the microscopic discharges) could further enhance the emission by a similar factor. Thus the probability of initiation of discharge during the operation of a pair of contacts greatly depends on the surface state of those contacts, and it might be expected that erosion would be greatly increased when those surfaces are dusty or covered with thin tarnish layers. Removal of such layers practically eliminates the discharges and the erosion, while the sweeping of positive ions to the layers greatly enhances the ernission.

In distinguishing between two types of films on metal surfaces, namely, tarnish films and grease films, Dr. J. C. Chaston (Johnson Matthey and Co., Ltd.) discussed the tarnishing of copper: in pure air (containing no sulphur) copper, although apparently clean, is covered by an oxide film $85 \mathrm{~A}$. thick which prevents further oxidation. The atmosphere, which both in town and country contains traces of hydrogen sulphide, produces a film of oxide and sulphide on copper about $450 \mathrm{~A}$. thick and reddishbrown in colour; but the thin oxide film, produced in pure air, will protect against the second. Properties of other contact metals were described. He raised a number of questions on the actual area of contact of two apparently plane surfaces, the welding of clean metal surfaces, the continuity or otherwise of the surface film at contact spots, the sticking of contacts, and the passage of current through films $20 \mathrm{~A}$. thick. D. O. Walter (Johnson Matthey and Co., Ltd.) dealt mainly with practical considerations in the design of light-duty sliding contacts, and he also discussed the properties of electrodeposited rhodium. Rhodium $(<0.001$ in. $)$ is often deposited on a silver substrate 0.0005 in. thick, and provides a useful contact surface, but the contact pressure must not be so high as to deform the silver substrate plastically. C. W. A. Mitchell and T. F. A. Urben (Telephone Branch, Post Office Engineering Department) gave an account of the exacting requirements of contact devices in telephone engineering, and discussed the use of various materials under a variety of mechanical conditions. Silver is generally used in low-voltage contacts : a ciné-film showed how contact bounce can be eliminated (or reduced) by proper mechanical design.

These papers were followed by discussion devoted mainly to the influence of tamish films; from this it may be concluded that light-duty contact operation is greatly determined by the nature of the contact surface, because that surface practically determines a whole train of microphysical phenomena.

The remaining papers related to heavy-duty contacts: Mr. Baxter (Electrical Research Association) reviewed factors causing wear, and Dr. Wilson (General Electric Co., Ltd.) discussed heavy contactors. R. W. Sillars (Metropolitan-Vickers Electrical Co., Ltd.) dealt with are suppression by associated circuits, T. H. Cook and M. Vaughan (Morgan Crucible Co., Ltd.) with brush contact efficiency, P. F. Soper (Northampton Polytechnic) with sliding contacts, and R. F. Sims (Royal Aircraft Establishment, Farnborough) with brush contacts operating at high altitudes. F. LLEWELLYN JoNes

\section{SUGGESTED REFORM OF THE INDIAN CALENDAR}

$A^{\mathrm{T}}$

$T$ the inaugural meeting of the Indian Astronomical and the Astrophysical Society of India, the president, Prof. M. N. Saha, gave an address on "The Reform of the Indian Calendar", which has recently been published (pp. 26 ; Indian Science News Association, 92 Upper Circular Road, Calcutta). Prof. Saha commenced by- explaining the problems of the calendar and described the different adjustments made by various nations in the past to obviate confusion; but in many cases the adjustments were responsible for raising more problems than they settled. He pointed out that, while the Christian calendar gives the length of the year correctly, it has a number of defects, such as the variation in the length of the months, the fact that the beginning of the month and of the year may fall on any day of the week, resulting in inconvenience to civic and economic activities, the use of the moon for determining certain Christian festivals and holidays, such as Easter, etc., and other inconveniences as well.

Prof. Saha went on to discuss two of the proposals that have been made to reform the Christian calendar 